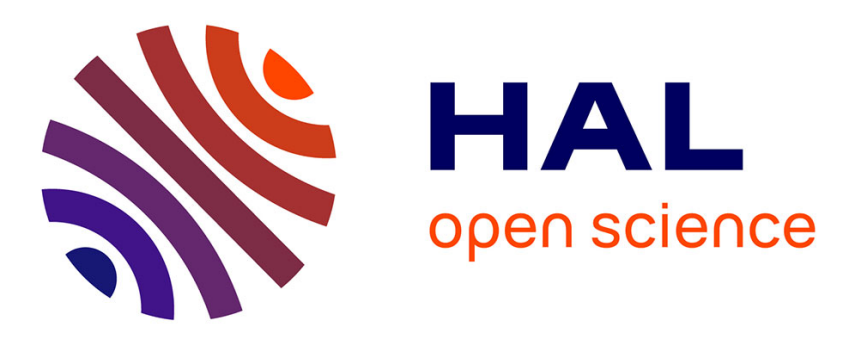

\title{
Maximum Solid Phase Concentration in Geophysical Turbulent Gas-Particle Flows: Insights From Laboratory Experiments
}

\author{
A. Weit, Olivier Roche, T. Dubois, M. Manga
}

\section{- To cite this version:}

A. Weit, Olivier Roche, T. Dubois, M. Manga. Maximum Solid Phase Concentration in Geophysical Turbulent Gas-Particle Flows: Insights From Laboratory Experiments. Geophysical Research Letters, 2019, 46 (12), pp.6388-6396. 10.1029/2019GL082658 . hal-02277038

\section{HAL Id: hal-02277038 \\ https://hal.uca.fr/hal-02277038}

Submitted on 18 Nov 2020

HAL is a multi-disciplinary open access archive for the deposit and dissemination of scientific research documents, whether they are published or not. The documents may come from teaching and research institutions in France or abroad, or from public or private research centers.
L'archive ouverte pluridisciplinaire HAL, est destinée au dépôt et à la diffusion de documents scientifiques de niveau recherche, publiés ou non, émanant des établissements d'enseignement et de recherche français ou étrangers, des laboratoires publics ou privés.

$$
\text { Copyright }
$$




\section{Lawrence Berkeley National Laboratory}

\section{Recent Work}

\section{Title}

Maximum Solid Phase Concentration in Geophysical Turbulent Gas-Particle Flows: Insights From Laboratory Experiments

Permalink

https://escholarship.org/uc/item/9n1505rs

Journal

Geophysical Research Letters, 46(12)

ISSN

0094-8276

Authors

Weit, A

Roche, $\mathrm{O}$

Dubois, $T$

et al.

Publication Date

2019-06-28

DOI

10.1029/2019GL082658

Peer reviewed 
Maximum Solid Phase Concentration in Geophysical Turbulent Gas-Particle Flows: Insights From Laboratory Experiments
A. Weit ${ }^{1}$, O. Roche ${ }^{1}$, T. Dubois ${ }^{2}$, and M. Manga ${ }^{3}$
${ }^{1}$ Laboratoire Magmas et Volcans, Université Clermont Auvergne, CNRS, IRD, OPGC, Clermont-Ferrand, France, ${ }^{2}$ Laboratoire de Mathématiques Blaise Pascal, Université Clermont Auvergne, CNRS, , Clermont-Ferrand, France, ${ }^{3}$ Department of Earth and Planetary Science, University of California, Berkeley, CA, USA

\section{Correspondence to: A. Weit, anne.weit@gmx.com}

\section{Abstract}

The maximum solid phase concentration in geophysical turbulent gasparticle mixtures is essential for understanding the flow dynamics but is poorly known. We present laboratory experiments on turbulent mixtures of air and ceramic particles generated in a vertical pipe. The mixtures had maximum bulk concentrations $C_{\max }=0.7-2.4$ vol. \% set by the onset of clustering and that increased with the degree of turbulence. Comparison with results of similar experiments with less dense (glass) particles reveals that $C_{\max }$ increases with the particle Reynolds number according to $C_{\max }=0.78 \times$ $\operatorname{Re}_{p}{ }^{0.17}$. Published results of experiments at specific $\mathrm{Re}_{\mathrm{p}}$ in different configurations are consistent with our data, suggesting that the model for $C_{\max }$ may be generally applicable to turbulent mixtures. From our empirical laws we infer that natural turbulent gas-particle flows with $R e_{p} \sim 10^{2}-10^{5}$ have maximum solid concentrations of $\sim 2-5$ vol. \%.

\section{Introduction}

Turbulent dilute mixtures of gas and solid particles are found in various geophysical contexts. They include dust storms (e.g., Goudie \& Middleton, 2001), powder snow avalanches (e.g., Carroll et al., 2013), and volcanic biphasic suspensions such as conduit flows, buoyant plumes, or pyroclastic density currents (e.g., Bonadonna et al., 2011; Carazzo \& Jellinek, 2012; Dufek, 2016; Gonnermann \& Manga, 2007). The concentration of particles controls the dynamics of these mixtures by changing their density and in some cases their thermal energy (Valentine \& Sweeney, 2018). The concentration is thought to be typically less than $\sim 1$ vol. \% (Andrews, 2014; Cantero et al., 2012; Lube et al., 2014). However, the maximum amount of solid particles that can be carried by a turbulent fluid and its possible dependence on the degree of turbulence (i.e., macroscopic or particle Reynolds numbers) are poorly known. For the case of pyroclastic density currents in which mean density and velocity are controlled by particle concentration, the dynamic pressure and volcanic hazard are sensitive to the unknown concentration. Uncertainty in particle concentration affects the interpretation of deposits in terms of flow duration, current velocity and current thickness, and sedimentation processes. 
Weit et al. (2018) investigated experimentally turbulent mixtures of air and glass beads in a vertical pipe as a function of the mixture Reynolds number,

$\operatorname{Re}_{\text {mix }}=\frac{\rho_{\text {mix }} U D}{\mu_{\text {mix }}}(1)$

with $U$ as the mean air flow velocity, $D$ as the pipe diameter, and $\rho_{\text {mix }}=C \rho_{\mathrm{s}}+$ $(1-C) \rho$ and $\mu_{\text {mix }}=(1+2.5 C) \mu$ as the density and the viscosity of the mixture, respectively, with $C$ as the mean particle volume concentration, $\rho_{s}$ as the particle density, $\rho$ as the air density, and $\mu$ as the air dynamic viscosity. Particles were either injected in the pipe or entrained from a dense bed to create a particle-air suspension. The mixtures had $R e_{\text {mix }} \sim 10^{4}-10^{6}$ and bulk maximum particle concentrations of $\sim 1-2.8$ vol. \%, which increased with $R e_{\text {mix. }}$. These dilute mixtures contained denser regions called clusters whose onset of formation coincided with the maximum bulk concentrations observed. The particle clusters segregated from the homogeneous mixture, settled downward, and formed a concentrated fluidized bed. A balance of particles cycling between the two regions set the maximum concentration of particles in the dilute mixture. Clustering has been the focus of numerous studies in engineering and fluid mechanics (e.g., Harris et al., 2002; Horio \& Kuroki, 1994; Neri \& Gidaspow, 2000). Though clustering is still not fully understood it is thought to be caused essentially by dissipation of the granular temperature arising from particle collisions (Dufek et al., 2012) and by hydrodynamic instabilities caused by relative motion between the particles and the carrier fluid phase (Fullmer \& Hrenya, 2017). Harris et al. (2002) showed that clusters in vertical risers had a variety of shapes, sizes, and velocities. The clusters moved downward in the annulus regions and upward in the core region, and they broke-up after formation, descended, and were reentrained in the upward flow. Most of these characteristics were observed as well by Weit et al. (2018). Clusters and their influence on the flow behavior have also been described in large-scale experiments simulating pyroclastic density currents (e.g., Breard et al., 2016), suggesting that clusters may be fundamental in controlling the dynamics of turbulent geophysical mixtures.

Weit et al. (2018) discussed implications of their experiments for natural systems, and they argued that the processes controlling the onset of clustering and hence the maximum particle concentrations in gas-particle mixtures could operate either at the flow scale (cf. macroscopic Reynolds number) or at the particle scale (cf. particle Reynolds number). The difference matters for extrapolation to the much larger length scales that characterize geophysical flows. In order to identify whether flow-scale and particle-scale processes are likely to control the threshold solid concentration, we carried out new experiments involving particle sizes and density different than that used by Weit et al. (2018). Here we compare both sets of results and discuss the control parameter of the maximum particle concentrations as well as implications for geophysical turbulent flows. 


\section{Methodology}

The experiments were carried out in a vertical pipe system consisting of two different parts (Figure 1). The lower part was the main experimental unit. It consisted of a perspex pipe in which turbulent biphasic mixtures were generated by first pouring particles onto a basal porous plate and then injecting air through the plate. The upper part served as a collection unit for the particles that escaped from the lower pipe whose top was covered by a grid. The mesh size of the grid was slightly larger than the grain size of the sieved particles used to generate the biphasic mixtures in order to avoid accumulation of particles in the interstices of the mesh. Two to three pressure sensors, with sampling frequencies of $100-200 \mathrm{~Hz}$, along the side of the pipe measured the fluid pressure of the gas-particle mixtures at different heights. The device was connected to an air compressor. A Photron Fastcam SA3 high-speed video camera recorded the experiments at rates of 500$1,000 \mathrm{frame} / \mathrm{s}$ and at a resolution of $1,024 \times 1,024$ pixels.

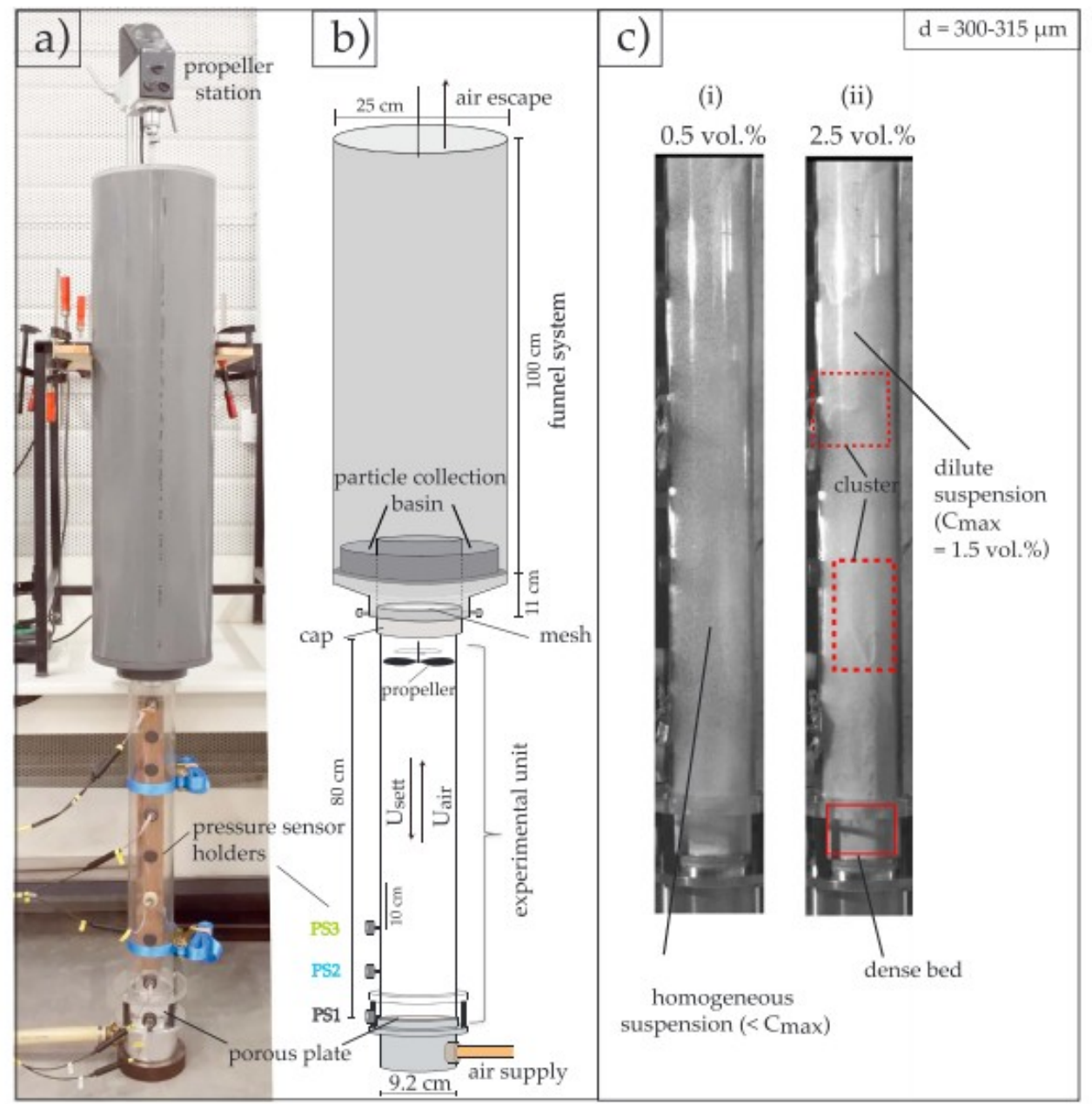

Figure 1. Experimental device used for the experiments. (a) Entire experimental setup with the lower experimental unit and the upper particle collection unit. (b) Sketch of the device. PS stands for pressure sensor. (c) Snapshots of high-speed videos. (i) At bulk initial particle concentration below the maximum concentration $C_{\max }$ : homogeneous turbulent suspension. (ii) At initial particle concentration above $C_{\max }$ : upper heterogeneous suspension with particle clusters and at concentration $C_{\max }$, and a lower dense bed. 
The upward air velocity was set to match the settling velocity of the particles in order to obtain a turbulent but quasi-static air-particle mixture, which was stable for $\sim 20 \mathrm{~s}$. The settling velocity was calculated using the method described in section 3.1 of Weit et al. (2018). We used five different size ranges of sieved ceramic beads with a density of $3,800 \mathrm{~kg} / \mathrm{m}^{3}$, with corresponding pure air flow velocities of up to $5.8 \mathrm{~m} / \mathrm{s}$. The experimental conditions for each grain size range, including mesh size, air flow properties, terminal settling velocity, dimensionless numbers, and the number of experiments performed are listed in Table 1 . The values of the mixture Reynolds number $>10^{5}$ ensured fully turbulent flow conditions. The particle Reynolds number is defined as

$\operatorname{Re}_{p}=\frac{\rho U d}{\mu}$

with $d$ as the particle diameter, $\rho=1.2 \mathrm{~kg} / \mathrm{m}^{3}$, and $\mu=1.8 \times 10^{-5}$ Pa.s. The Stokes number is defined as the ratio of the particle drag response time $\sim\left(\rho_{s}-\rho\right) d^{2} / \mu$ over the overturn time of an eddy $D / U$, so that

$S t=\frac{\left(\rho_{s}-\rho\right) U d^{2}}{\mu D}$

Table 1

\begin{tabular}{|c|c|c|c|c|c|c|}
\hline Particle size $(\mu \mathrm{m})$ & $106-125$ & $160-180$ & $300-315$ & $450-475$ & $710-750$ & $300-315$ (ceramic) $/ 450-475$ (glass) \\
\hline Mesh size $(\mu \mathrm{m})$ & 180 & 315 & 450 & 630 & 800 & 630 \\
\hline$Q(\mathrm{~L} / \mathrm{min})$ & 400 & 600 & 1,150 & 1,550 & 2,300 & 1,150 \\
\hline$U(\mathrm{~m} / \mathrm{s})$ & 1.0 & 1.5 & 2.9 & 3.9 & 5.8 & 2.9 \\
\hline$U_{t}(\mathrm{~m} / \mathrm{s})$ & 1.02 & 1.59 & 3.1 & 4.5 & 6.8 & 3.1 \\
\hline$R e_{\text {air }}$ & $5.9 \times 10^{3}$ & $8.9 \times 10^{3}$ & $1.7 \times 10^{4}$ & $2.3 \times 10^{4}$ & $3.4 \times 10^{4}$ & $1.7 \times 10^{4}$ \\
\hline$R e_{\text {mix }}$ & $1.5 \times 10^{5}$ & $2.5 \times 10^{5}$ & $7.9 \times 10^{5}$ & $1.5 \times 10^{6}$ & $2.1 \times 10^{6}$ & $7.9 \times 10^{5}$ \\
\hline$R e_{p}$ & 7.4 & 16.5 & 57 & 114 & 273 & 72 \\
\hline$S t$ & $2.6 \times 10^{5}$ & $5.7 \times 10^{5}$ & $2.0 \times 10^{6}$ & $3.9 \times 10^{6}$ & $9.4 \times 10^{6}$ & $2.1 \times 10^{6}$ \\
\hline$\eta(\mathrm{m})$ & $1.3 \times 10^{-5}$ & $8.0 \times 10^{-6}$ & $3.4 \times 10^{-6}$ & $2.1 \times 10^{-6}$ & $1.6 \times 10^{-6}$ & $3.4 \times 10^{-6}$ \\
\hline$C_{\max ,(\text { mean) }}$ & 0.8 & 0.9 & 1.5 & 2.1 & 1.9 & 1.8 \\
\hline$C_{\max }$ (range) & $0.7-0.9$ & $0.7-1.1$ & $1.3-2$ & $2-2.4$ & $1.7-2.2$ & $1.7-1.9$ \\
\hline Mass fraction & 0.96 & 0.97 & 0.98 & 0.99 & 0.98 & \\
\hline Number of experiments (single measurements) & $5(119)$ & $5(119)$ & $6(152)$ & $4(100)$ & $4(100)$ & $3(75)$ \\
\hline
\end{tabular}

Note. Q: air flow rate; U: mean air flow velocity; $U_{t}$ : theoretical particle terminal fall velocity; $\operatorname{Re}_{\text {air }}$ and $\operatorname{Re}_{\text {mix }}$ : Reynolds numbers of the pure air flow and of the gas-particle mixture (equation (1)) at maximum particle concentration $C_{\max }$, respectively; $\mathrm{Re}_{\mathrm{p}}$ : particle Reynolds number (equation (2)); St: Stokes number (equation (3)); $\eta$ : Kolmogorov length scale $\sim \mathrm{Re}_{\text {air }}{ }^{-3 / 4} \mathrm{D}$ (with $\mathrm{D}$ the pipe diameter); $C_{\max }$ (mean): mean maximum particle concentration for the number of experiments performed; and $C_{\max }$ (range): range of measured maximum particle concentrations per grain size. Mean grain sizes were considered for calculating $\mathrm{Re}_{\text {mix }}, \mathrm{Re}_{\mathrm{p}}$, and $\mathrm{St}$ ( $385 \mu \mathrm{m}$ for the ceramic/glass mixture).

We choose a length scale $D$ for the flow timescale because cluster size and eddy size are limited by $D$. Note that a correction for the particle drag response time may be used (Cerminara et al., 2016) but has little influence on our results (Supporting Information S4). We also carried out one complementary experiment involving a mixture of ceramic and glass particles (the latter with a density of $2,500 \mathrm{~kg} / \mathrm{m}^{3}$ ) that had about the same settling velocity and were in equal volume proportion (Table 1 ).

Bulk particle concentrations in the pipe, defined by the ratio of the volume of the particles and the volume of the pipe, between 0.25 and 3.25 vol. \% were used in steps of 0.10 vol. \% (i.e., $21.5 \pm 0.01 \mathrm{~g}$ ) or 0.25 vol. \%. A total of 27 experiments (665 single measurements) for all five grain size ranges and the 
ceramic-glass mixture were carried out. One experiment consisted of up to 25 runs including two measurements per run, a first standard measurement (pure air flow without particles) and a second measurement with a known bulk particle volume concentration in the pipe. The maximum particle concentrations were determined from the pressure measurements.

3 Results

\subsection{General Observations}

The turbulent mixtures of air and ceramic particles were homogeneous up to the measured maximum particle concentration, $C_{\max }$, which increased with the degree of turbulence and varied from 0.7 to 2.4 vol. \% (Figure 1 and Table 1). Clusters formed above this maximum concentration and rendered the mixtures heterogeneous (Figure 1). They appeared as elongated deforming denser regions and usually moved upward in the pipe center but always downward in outer regions. The clusters had terminal fall velocities larger than that of a single particle, and hence, they settled and led to the formation of a relatively thin dense fluidized bed at the bottom of the column underneath a larger upper dilute region at particle concentration $C_{\max }$. The dense fluidized bed regenerated continuously because of the supply of particles from settling clusters and of the loss of particles injected into the dilute mixture due to air flow passing through the bed. It was highly agitated, and due to high expansion in some cases for particle sizes of 300-315 $\mu \mathrm{m}$ and larger pressure sensor 2 (PS2; Figure 1) could not be used to determine the particle concentration in the upper dilute part, and hence, pressure sensor 3 (PS3) was used.

\subsection{Particle Concentrations and Comparison With Earlier Experiments}

For all the grain size ranges and the binary ceramic/glass mixture, the pressure measured by the sensor at the base (PS1) was close to the theoretical pressure equal to the weight of the particles divided by the crosssectional area of the pipe, indicating that the weight of the particles was almost entirely supported by air drag and transmitted to the sensor through the interstitial air (Figure 2). Measurements above the basal fluidized bed with either pressure sensors PS2 or PS3 showed an increase of the pressure until the maximum concentration threshold, which was followed by a stagnation of the pressure. In some cases (Figure $2 \mathrm{~b}$ ) the pressure slightly increased or decreased above the maximum concentration threshold. We have no explanation for the origin of this phenomenon, which might however be due to differences in cluster size and frequency for different particle sizes considered. Notice that the increase or decrease in particle concentration, when present, was weak. We recall that our focus was the determination of $C_{\max }$ at the onset of clustering. The data revealed a gap between the theoretical pressure and that measured by the sensors, which we attribute to local higher particle concentration in the dilute mixture close to the fluidized bed, meaning there were fewer particles than theoretically predicted above 
the sensor assuming a homogeneous mixture (videos of the experiments confirmed an increase of the particle concentration toward the dense bed).
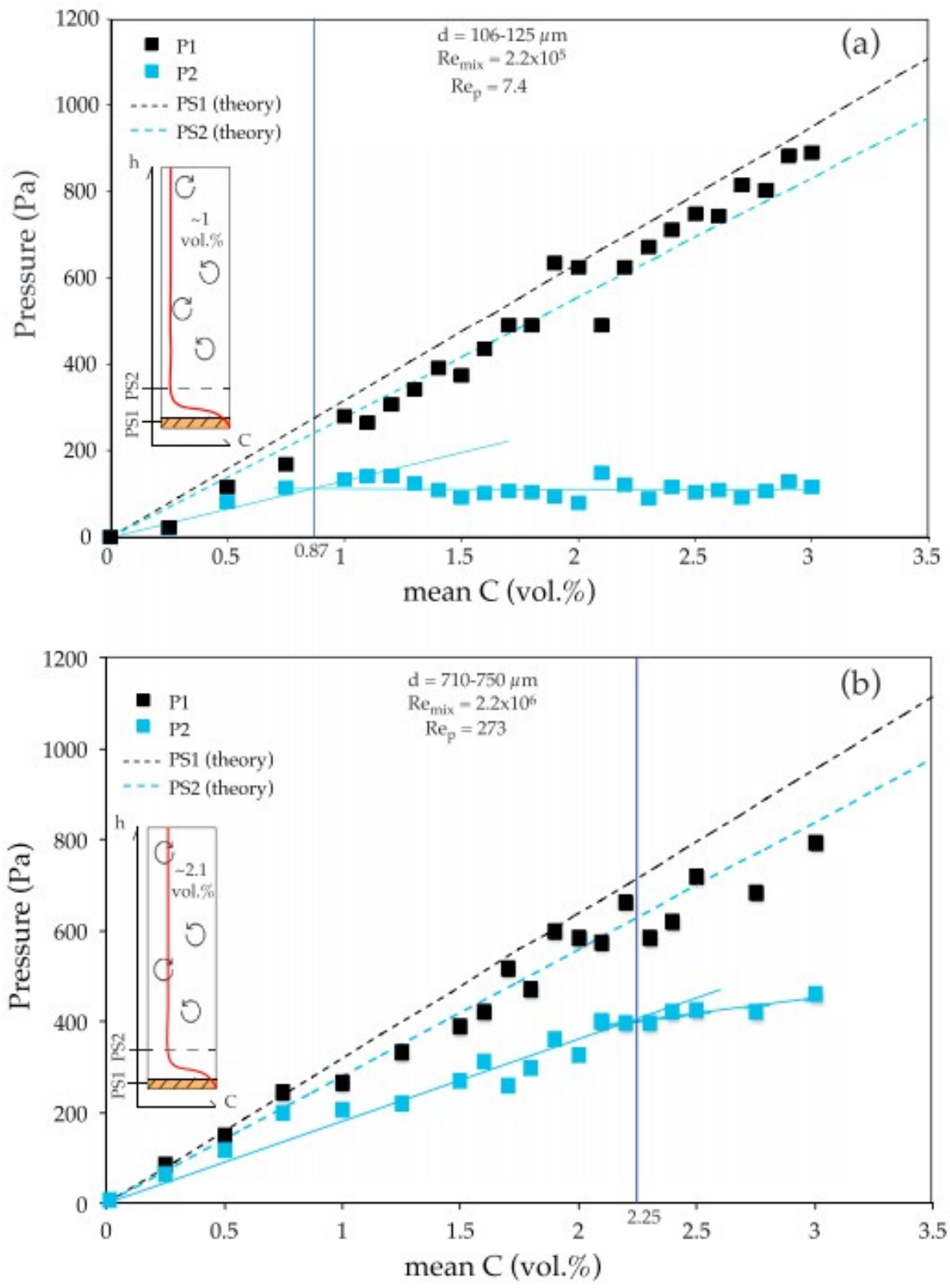

Figure 2. Pressure measurements for mixtures with ceramic beads of size (a) 106-125 $\mu \mathrm{m}$ or (b) $710-750 \mu \mathrm{m}$. The theoretical values for pressure sensors PS1 and PS2 were calculated from the weight of the particles that would be present above a given sensor, assuming a homogenous particle concentration, divided by the cross sectional area of the pipe (dashed lines). The mean maximum particle concentrations of the dilute mixtures are given by the dark blue lines obtained from intersection of the pressure curves. The sketches visualize the particle distributions (red curves) within the device.

The maximum mean particle concentration in the dilute mixture was determined from the data of sensors PS2 or PS3 by considering the break in slope of the pressure curves. The data for $C_{\max }$ are given in Figure 3 as a 
function of $R e_{\text {mix }}$ or $R e_{p}$, and they are compared with the data of experiments with glass beads of Weit et al. (2018). The maximum volume concentrations for the ceramic or glass particles are $\sim 0.7-2.4$ vol. \% and increase with $R e_{\text {mix }}$ and $R e_{p}$. The range of $C_{\max }$ for a given particle size is typically less than $0.2-$ 0.6 vol. \%. Figure 3 shows that when $C_{\max }$ is plotted against $R e_{\operatorname{mix}}$, the data for both types of particles define two distinct trends, and the concentrations for the ceramic particles are in general lower than for glass particles. However, the trends collapse fairly well if the data are plotted against $R e_{p}$, hence giving a main trend of $C_{\max }=0.78 \times R e_{p}{ }^{0.17}$ for all experiments with both particle types. Notice that (i) $C_{\max }$ measured for the binary mixture is very close to the value given by the main trend; (ii) if $R e_{p}$ is defined considering the density and the viscosity of the mixture, instead of that of the pure air, then the main trend is very close to that described above (Supporting Information S1); and (iii) the power law obtained considering St, that is, $C_{\max }=0.16 \times S t^{0.16}$, is slightly different than for $R e_{p}$ because ceramic and glass beads have different densities (Supporting Information S3 and S4). Conversion of particle volume concentration to bulk mixture density, which varies from $\sim 30$ to $\sim 90 \mathrm{~kg} / \mathrm{m}^{3}$ (Supporting Information S2), shows that the ceramic and glass particles have very different dependencies on $R e_{p}$. Bulk densities for both particle types overlap at low $R e_{p}$, and the trends diverge for $\operatorname{Re}_{p}$ greater than about 20. 

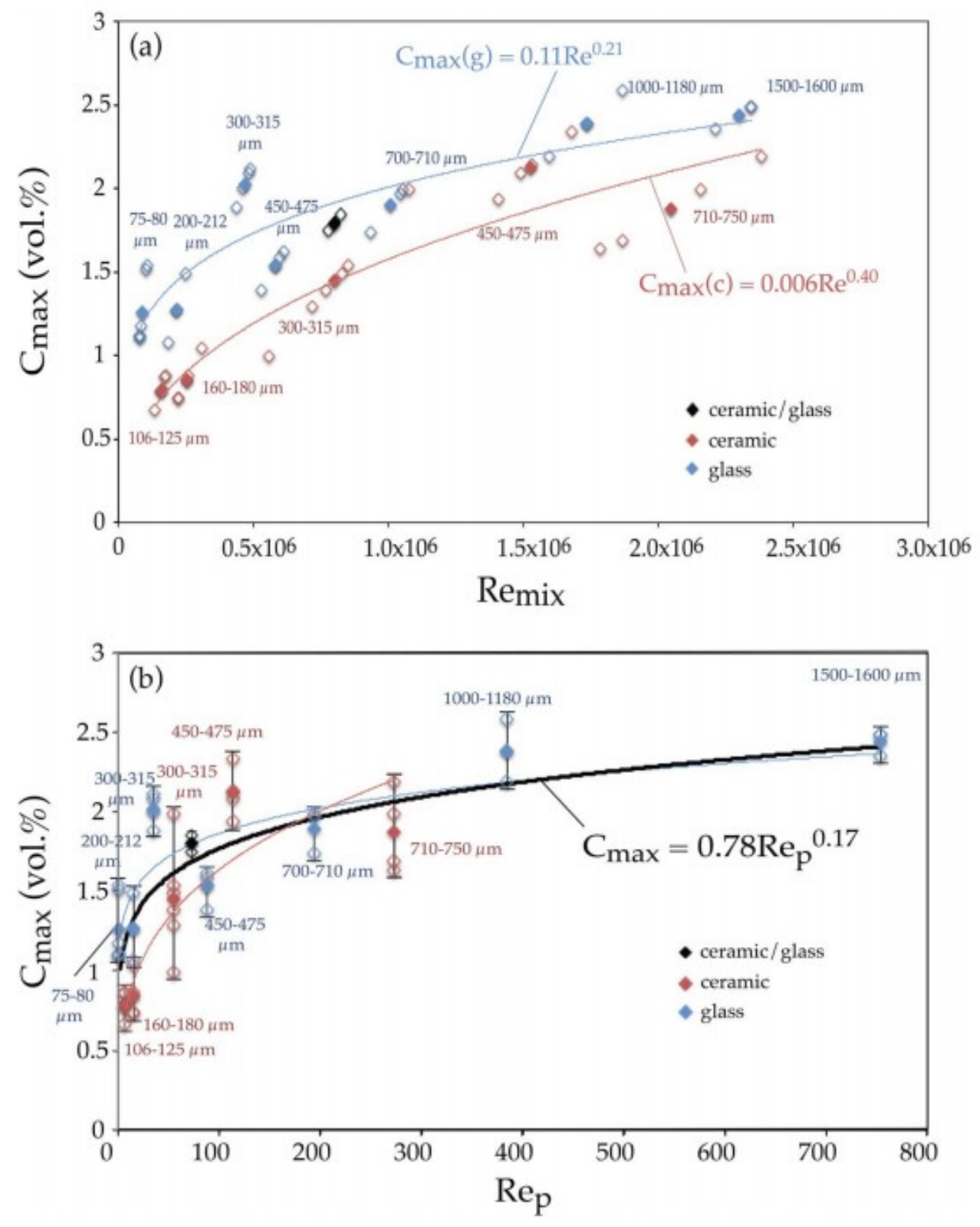

Figure 3. Maximum solid volume concentrations of mixtures with ceramic particles (this study) or glass particles (Weit et al., 2018) as function of (a) the mixture Reynolds number or (b) the particle Reynolds number. Grain size ranges are given.

\section{Discussion}

We now discuss the maximum solid concentrations observed in our experiments as well as implications for natural flows. Our results suggest that processes at the particle scale (cf. $R e_{p}$ ) control the maximum particle concentration in turbulent biphasic mixtures. This is consistent with the fact that $C_{\max }$ is set by particle clustering, which is caused, along with particle collisions, by hydrodynamic instabilities occurring at the particle scale (Fullmer \& Hrenya, 2017). $C_{\max }$ is greater than the value, $\sim 10^{-3}$, at which 
four-way coupling controls dynamics (e.g., Elghobashi, 1994), where fourway coupling means that the particles and gas interact with each other, and particle-particle interactions affect dynamics as well. But specifying how these instabilities ultimately control $C_{\max }$ is not straightforward because no detailed analytical description of clustering is available in literature nor are we able to develop a model. Further, the Stokes number is large enough that numerical simulations require fully resolved direct numerical simulation (Balachandar \& Eaton, 2010). The similar trends for $R e_{p}$ and $S t$ we found, owing to the relatively small variation of the ratio of the particle density to that of the ambient air, do not permit us to conclude whether fluid inertia (cf. $R e_{p}$ ) or particle inertia (cf. St) is the dominant effect on clustering.

Our data, however, suggest that hydrodynamic instabilities may be more efficient for promoting clustering, and hence lower values of $C_{\max }$, at low values of $R e_{p}$ that characterize the transitional regime between laminar and fully turbulent conditions $\left(R e_{p}\right.$ of the order of $\sim 10^{1}-10^{2}$ is commonly cited for the lower limit of the turbulent regime; Jeffrey \& Pearson, 1965) and at low values of $S t$ that characterize better fluid-particle coupling. There is broad consensus that preferential concentration is most important for St $\sim 1$ (e.g., Balachandar \& Eaton, 2010; Fessler et al., 1994; Sundaram \& Collins, 1997) because decreasing granular temperature related to particle collisions with decreasing degree of turbulence increases fluid-particle coupling to enhance clustering. Whether both hydrodynamic instabilities and particle collisions favor clustering at low values of $R_{p}$ or St remains an open question and not one for which our experiments can provide new insights. In order to stimulate further research on this issue, however, we highlight that at low values of $R e_{p}$ or $S t$, clustering might depend on a critical mass of the solid phase in the mixture since the data for mass concentrations of both particle types collapse (Supporting Information S2). Attributing the maximum particle concentration to clustering is an alternative to the model of Cantero et al. (2012) for water-particle turbidity currents, which assumes suppression of fluid turbulence when a solid concentration threshold is reached.

Our empirical law $C_{\max }=0.78 \times R e_{p}^{0.17}$ is compared in Figure 4 with the results of experiments of Lu et al. (2009) on gas-particle riser flows and of Breard et al. (2016) on analogue pyroclastic density currents. In Lu et al. (2009) an air flow at velocity larger than the particle settling velocity and passing through a packed bed entrained particles upward and generated a dilute mixture. In contrast, in experiments of Breard et al. (2016), a dilute mixture collapsed under gravity onto a rigid substrate and deflated to form a highly concentrated lateral flow. In both cases, a transitional state from high to low concentrations existed, where clusters were most evident. In the riser configuration, for example, the clusters typically showed particle concentrations of 10-15 vol. \% (Chen et al., 2016). Our configuration involving clusters forming and settling in a dilute suspension is closer to that of Breard et al. (2016) than that of Lu et al. (2009) in terms of flow dynamics. 


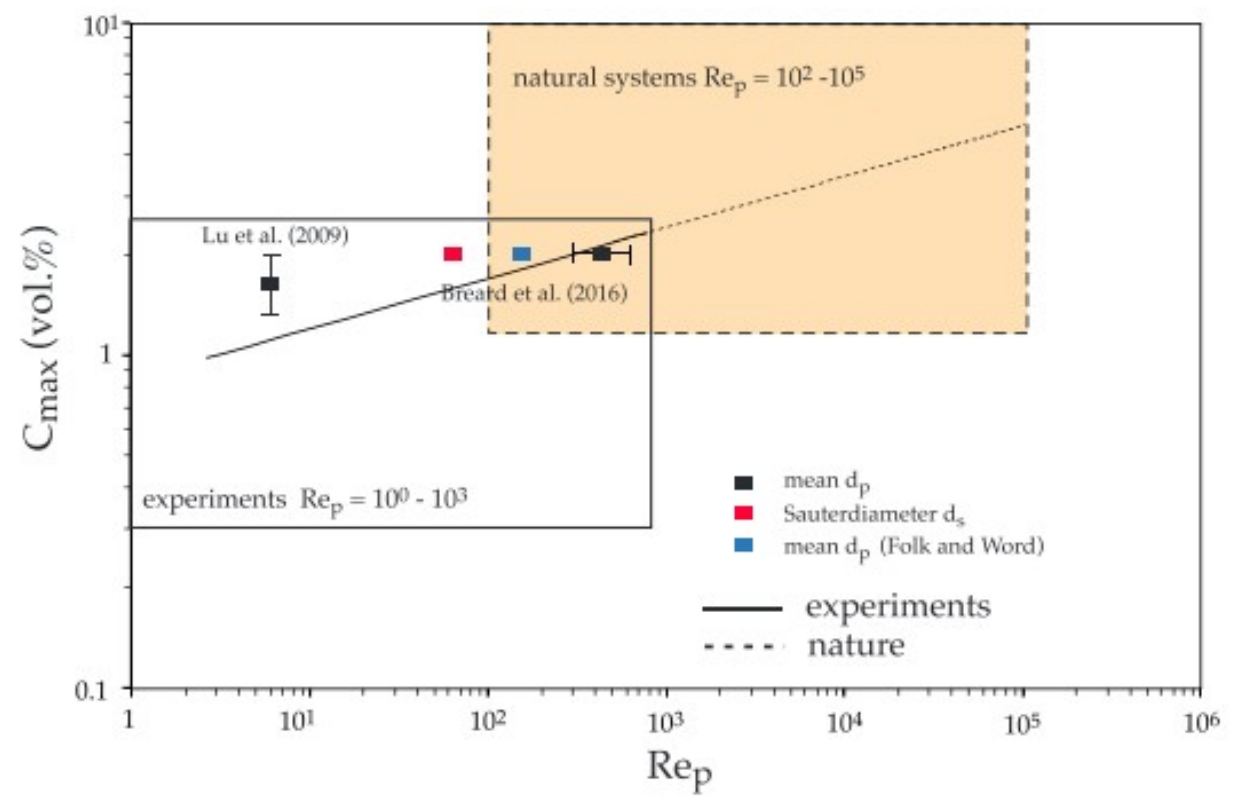

Figure 4. Maximum particle volume concentration as a function of the particle Reynolds number in our experiments $\left(C_{\max }=0.78 \times R e_{p}{ }^{0.17}\right)$, and values inferred for gas-particle geophysical mixtures with $R e_{p}=10^{2}-10^{5}$. Results of experiments of Lu et al. (2009) and of Breard et al. (2016) are indicated. For Breard et al. (2016) we considered the mean Folk and Ward diameter (blue square) or the Sauter diameter (red square, see Breard et al., 2018).

Interestingly, the data of Breard et al. (2016), that is, particle concentration of $\sim 1.6-2.2 \mathrm{vol} . \%$ and $R e_{p} \sim 65-160$ in the cluster-rich region, are in very good agreement with our findings. We calculated $R e_{p}$ from the flow velocity $\sim 10 \mathrm{~m} / \mathrm{s}$, the mean grain size $\sim 100-250 \mu \mathrm{m}$, and the particle density $\sim 2,000$ $\mathrm{kg} / \mathrm{m}^{3}$ given for the region containing clusters (called $\mathrm{CL}$ ) in Figure 4 and Supplementary Material of Breard et al. (2016). The particle concentration of $\sim 1.5-2$ vol. \% at $R e_{p} \sim 5$ in Lu et al. (2009) is slightly larger than predicted by our empirical law ( $\sim 1$ vol. \%). In Figure 4 , the experimental law is extrapolated to infer maximum particle concentrations in geophysical gasparticle turbulent flows. Considering dilute pyroclastic density currents with $R e_{\text {mix }}$ up to $\sim 10^{9}-10^{10}$ and containing particles with maximum sizes of $1-10$ $\mathrm{cm}$ and typical densities of $1,000-2,500 \mathrm{~kg} / \mathrm{m}^{3}$, having terminal settling velocities of $20-80 \mathrm{~m} / \mathrm{s}$, then $R e_{p} \sim 10^{2}-10^{5}$ (Figure 4). Assuming that the empirical law is applicable at $R e_{p}>10^{3}$, we find maximum particle concentrations of $\sim 2-5$ vol. \%. These maximum concentrations are likely to be achieved when biphasic mixtures evolve from dense to dilute, or vice versa, and as clusters typical of the transient intermediate concentration state segregate in a transition zone as shown by Lu et al. (2009) and Breard et al. (2016).

Our experiments also provide insights into the dynamics and structure of gravitational geophysical gas-particle flows such as pyroclastic density currents generated from column collapse. These could consist fundamentally of (i) a concentrated basal layer with particles transported in a granular 
regime and (ii) an upper dilute layer with particles carried by the turbulent fluid, which has mean concentrations close to $C_{\max }$ at early stages and then decreasing as the ambient fluid is incorporated while the flow propagates. This conceptual model is consistent with the observations of Breard et al. (2016) for propagating density currents.

\section{Conclusions}

Through laboratory experiments we addressed the issue of the maximum particle concentration in dilute turbulent gas-particle mixtures. We conclude with the following remarks.

1. Mixtures of air and ceramic particles had maximum solid concentrations set by clustering. The maximum concentrations of the mixtures were 0.7-2.4 vol. \% and increased with the particle Reynolds number.

2. Our data combined with those of earlier experiments show that the maximum particle volume concentration in gas-particle mixtures varies with the particle Reynolds number according to $C_{\max }=0.78 \times R e_{p}^{0.17}$. This is consistent with clustering caused by processes such as hydrodynamic instabilities occurring at the particle scale.

3. We infer from our experimental laws that geophysical turbulent gasparticle flows with particle Reynolds numbers $\sim 10^{2}-10^{5}$ have maximum solid phase concentrations of $\sim 2-5$ vol. \%.

\section{Acknowledgments}

This research was financed by the French National Research Agency (ANR) RAVEX project, by the French National Research Institute for Sustainable Development (IRD), and by the French Government Laboratory of Excellence initiative ANR-10-LABX-0006 through a doctoral scholarship (A. Weit). M. M. is supported by NSF 1447559. This is Laboratory of Excellence ClerVolc contribution 352. The data used are listed in the references, tables, and supporting information. We thank Cyrille Guillot for constructing the device and for his valuable technical expertise and Ben Andrews and an anonymous reviewer for insightful reviews.

\section{References}

Andrews, B. J. (2014). Dispersal and air entrainment in unconfined dilute pyroclastic density currents. Bulletin of Volcanology, 76( 9), 1- 14. https://doi.org/10.1007/s00445-014-0852-4

Balachandar, S., \& Eaton, J. K. (2010). Turbulent dispersed multiphase flow. Annual Review of Fluid Mechanics, 42( 1), 111- 133. https://doi.org/10.1146/ annurev.fluid.010908.165243

Bonadonna, C., Genco, R., Gouhier, M., Pistolesi, M., Cioni, R., Alfano, F., Hoskuldsson, A., \& Ripepe, M. (2011). Tephra sedimentation during the 2010 Eyjafjallajkull eruption (Iceland) from deposit, radar, and Satellite 
Observations. Journal of Geophysical Research, 116, B12202. https://doi.org/ 10.1029/2011JB008462

Breard, E. C. P., Dufek, J., \& Lube, G. (2018). Enhanced mobility in concentrated pyroclastic density currents: An examination of a self-

fluidization mechanism. Geophysical Research Letters, 45, 654- 664. https:// doi.org/10.1002/2017GL075759

Breard, E. C. P., Lube, G., Jones, J. R., Dufek, J., Cronin, S. J., Valentine, G. A., $\&$ Moebis, A. (2016). Coupling of turbulent and non-turbulent flow regimes within pyroclastic density currents. Nature Geoscience, 9(10), 767- 771. https://doi.org/10.1038/ngeo2794

Cantero, M. I., Shringarpure, M., \& Balachandar, S. (2012). Towards a universal criteria for turbulence suppression in dilute turbidity currents with non-cohesive sediments. Geophysical Research Letters, 39, L14603. https://doi.org/10.1029/2012GL052514

Carazzo, G., \& Jellinek, M. A. (2012). A new view of the dynamics, stability and longevity of volcanic clouds. Earth and Planetary Science Letters, 325326, 39- 51. https://doi.org/10.1016/j.epsl.2012.01.025

Carroll, C. S., Louge, M. Y., \& Turnbull, B. (2013). Frontal dynamics of powder snow avalanches. Journal of Geophysical Research: Earth Surface, 118, 913924. https://doi.org/10.1002/jgrf.20068

Cerminara, M., Eposti Ongaro, T., \& Berselli, L. C. (2016). ASHEE-1.0: A compressible, equilibrium-Eulerian model for volcanic ash plumes.

Geoscientific Model Development, 9( 2), 697- 730.

https://doi.org/10.5194/gmd-9-697-2016

Chen, C., Dai, Q., \& Qi, H. (2016). Improvement of EMMS drag model for heterogeneous gas-solid flows based on cluster modeling. Chemical Engineering Science, 141, 8- 16. https://doi.org/10.1016/j.ces.2015.10.025

Dufek, J. (2016). The fluid mechanics of pyroclastic density currents. Annual Review of Fluid Mechanics, 48( 1), 459- 485.

https://doi.org/10.1146/annurev-fluid-122414-034252

Dufek, J., Manga, M., \& Patel, A. (2012). Granular disruption during explosive volcanic eruptions. Nature Geoscience, 5( 8), 561- 564.

https://doi.org/10.1038/ngeo1524

Elghobashi, S. (1994). On predicting particle-laden turbulent flows. Applied Scientific Research, 52( 4), 309- 329. https://doi.org/10.1007/BF00936835

Fessler, J. R., Kulick, J. D., \& Eaton, J. K. (1994). Preferential concentration of heavy particles in a turbulent channel flow. Physics of Fluids, 6(11), 37423749. https://doi.org/10.1063/1.868445

Fullmer, W. D., \& Hrenya, C. M. (2017). The clustering instability in rapid granular and gas-solid flows. Annual Review of Fluid Mechanics, 49( 1), 485510. https://doi.org/10.1146/annurev-fluid-010816-060028 
Gonnermann, H. M., \& Manga, M. (2007). The fluid mechanics inside a volcano. Annual Review of Fluid Mechanics, 39( 1), 321- 356. https://doi.org/ 10.1146/annurev.fluid.39.050905.110207

Goudie, A. S., \& Middleton, N. J. (2001). Saharan dust storms: Nature and consequences. Earth-Science Reviews, 56( 1-4), 179- 204. https://doi.org/10.1016/S0012-8252(01)00067-8

Harris, A. T., Davidson, J. F., \& Thorpe, R. B. (2002). The prediction of particle cluster properties in the near wall region of a vertical riser (200157). Powder Technology, 127( 2), 128- 143. https://doi.org/10.1016/S00325910(02)00114-6

Horio, M., \& Kuroki, H. (1994). Three-dimensional flow visualization of dilutely dispersed solids in bubbling and circulating fluidized beds. Chemical Engineering Science, 49( 15), 2413- 2421. https://doi.org/10.1016/00092509(94)E0071-W

Jeffrey, R., \& Pearson, J. (1965). Particle motion in laminar vertical tube flow. Journal of Fluid Mechanics, 22( 04), 721- 735. https://doi.org/10.1017/S0022112065001106

Lu, B., Wang, W., \& Li, J. (2009). Searching for a mesh-independent sub-grid model for CFD simulation of gas-solid riser flows. Chemical Engineering Science, 64( 15), 3437- 3447. https://doi.org/10.1016/j.ces.2009.04.024

Lube, G., Breard, E. C. P., Cronin, S. J., Procter, J. N., Brenna, M., Moebis, A., Pardo, N., Stewart, R. B., Jolly, A., \& Fournier, N. (2014). Dynamics of Surges Generated by Hydrothermal Blasts during the 6 August 2012 Te Maari Eruption, Mt. Tongariro, New Zealand. Journal of Volcanology and Geothermal Research, 286, 348- 366.

https://doi.org/10.1016/j.jvolgeores.2014.05.010

Neri, A., \& Gidaspow, D. (2000). Riser hydrodynamics: Simulation using kinetic theory. AICHE Journal, 46( 1), 52- 67.

https://doi.org/10.1002/aic.690460108

Sundaram, S., \& Collins, L. R. (1997). Collision statistics in an isotropic particle-laden turbulent suspension. Part 1. Direct numerical simulations. Journal of Fluid Mechanics, 335, 75- 109. https://doi.org/10.1017/S0022112096004454

Valentine, G. A., \& Sweeney, M. R. (2018). Compressible flow phenomena at inception of lateral density currents fed by collapsing gas-particle mixtures. Journal of Geophysical Research: Solid Earth, 123, 1286- 1302. https://doi.org/10.1002/2017JB015129

Weit, A., Roche, O., Dubois, T., \& Manga, M. (2018). Experimental measurement of the solid particle concentration in geophysical turbulent gas-particle mixtures. Journal of Geophysical Research: Solid Earth, 123, 3747- 3761. https://doi.org/10.1029/2018JB015530 